Check for updates

The BMJ

Cite this as: BMJ 2020;371:m4906 http://dx.doi.org/10.1136/bmj.m4906 Published: 17 December 2020

\title{
Covid-19: Wales tightens Christmas restrictions as four nations' rules diverge
}

Clara Munro

The Welsh government has broken ranks with the rest of the UK by imposing stronger restrictions over the Christmas period, limiting the number of households that can meet to two. ${ }^{1}$ Rules have also been tightened in Scotland, although those in England and Northern Ireland are essentially unchanged.

This is despite a warning from Fiona Godlee and Alastair McLellan, editors of The BMJ and HSJ respectively, that relaxation of the rules over Christmas will place more pressure on NHS beds and force cancellation of elective services that have only just started to recover. ${ }^{2}$

The move in Wales follows a surge in covid-19 cases. First minister Mark Drakeford said on 16 December that there were more than 2100 people with coronavirus symptoms in Welsh

hospitals-equivalent to five general hospitals fully occupied by people with coronavirus.

On 17 December it emerged that the number of cases was higher than previously thought after Public Health Wales said that 11 ooo cases were missed from the figures because of "planned maintenance" of IT systems. Figures for the week ending 15 December currently stand at 11911 , but the extra cases would nearly double this figure.

Drakeford confirmed that the current conditions mean that Wales has met the criteria in the new Coronavirus Control Plan to move to alert level 4. This means that all non-essential retail, including close contact services and all leisure and fitness centres, will close at the end of trading on Christmas Eve and all hospitality premises will close from $6 \mathrm{pm}$ on Christmas Day. From 28 December tighter restrictions on household mixing, holiday accommodation, and travel will apply.

The limits on two households meeting over Christmas, plus an additional single person if they live alone, will become law.

Drakeford said, "We are seeing levels of coronavirus in some parts of the country that we haven't experienced at any point before in this pandemic. This pandemic is putting our NHS under intense and sustained strain.

"This has been such a long and difficult year. We need to take this action to save lives and control the spread of this virus. A smaller Christmas is a safer Christmas and a shorter Christmas is a safer Christmas."

\section{Scotland}

Nichola Sturgeon, first minister for Scotland has advised that the "safest way to spend Christmas is to celebrate with your own household in your own home," but recognised the risk of loneliness and isolation. ${ }^{3}$

She said that up to three households can form a bubble, but recommended keeping the maximum to eight people aged 12 and over. People were also advised to meet up only on one day and to avoid staying overnight and travelling between high and low prevalence areas.

\section{England and Northern Ireland}

Prime Minister Boris Johnson and First Minister Arlene Foster reiterated that Christmas should be smaller and shorter in order to remain safer. Five days should be seen as a legal maximum and not a target. ${ }^{4}$ Three households can form a Christmas bubble for five days between 23 and 27 December, with no upper limit, although people are encouraged to keep their bubble as small as possible.

Welsh Government. Higher level restrictions to come into force to control coronavirus. December 2020.

https://gov.wales/higher-level-restrictions-come-force-control-coronavirus.

2 McLellan A, Godlee F. Covid 19: Christmas relaxation will overwhelm services. BM/2020;371:m4847. doi: 10.1136/bmj.m4847 pmid: 33323367

3 Scottish Government. Coronavirus: Christmas and the festive period. 16 December 2020.

www.gov.scot/publications/coronavirus-covid-19-guidance-for-festive-period.

4 Cabinet Office. Making a Christmas bubble with friends and family. 16 December 2020. www.gov.uk/government/publications/making-a-christmas-bubble-with-friends-and-family/making-a-christmas-bubble-withfriends-and-family.

5 Northern Ireland Government. Coronavirus (covid-19) regulations guidance: restrictions for Christmas. www.nidirect.gov.uk/articles/coronavirus-covid 19-regulations-guidance-restrictions-christmas. 